\title{
Studi Manajemen Risiko Kesehatan dan Keselamatan Kerja dengan Metode HIRAC (Studi Kasus : Pada Proyek Pembangunan Apartemen Tamansari Amarta Yogyakarta)
}

\author{
Widi Hartono1), Sugiyarto's), Arumsya Hening P. R.3), dan Pangestuti Siwi R. 4) \\ 1) Pengajar Fakultas Teknik, Prodi Teknik Sipil, Universitas Sebelas Maret \\ 2) Pengajar Fakultas Teknik, Prodi Teknik Sipil, Universitas Sebelas Maret \\ 3) Mahasiswa Fakultas Teknik, Prodi Teknik Sipil, Universitas Sebelas Maret \\ 4) Mahasiswa Fakultas Teknik, Prodi Teknik Sipil, Universitas Sebelas Maret \\ Jl. Ir. Sutami 36A, Surakarta 57126; Telp. 0271-634524. Email: arumsyaheningp@gmail.com
}

\begin{abstract}
The number of occupational accidents in Indonesia is still very high in 2018 from the BPJS data. Workforce employment recorded 157,313 cases and construction work was the highest contributor to work accident cases. Based on these data, research is conducted on why this can happen, what factors are the causes of workplace accidents and how the work accident planning and management system in construction projects. This study used the interview method and questionnaire distribution which was distributed to the person in charge of safety, namely HSE. The research instrument used refers to Form HIRAC with 3 stages of filling HIRAC namely hazard identification, risk assessment and hazard control. Based on the analysis and discussion on the Tamansari Amarta apartment development project it can be concluded that the highest risk is in the formwork slab work and column installation work. Both jobs have the risk of workers tripping over material and workers being scratched or pierced by material. The control effort carried out is by implementing a hierarchical control system. It starts with the elimination stage, continues the administration stage related to work operational standards (SOP), and the last is the use of personal protective equipment (PPE).
\end{abstract}

Key words: risk management, HIRAC, occupational accident.

\begin{abstract}
Abstrak
Angka kecelakaan kerja di Indonesia masih sangat tinggi pada tahun 2018 dari data BPJS Ketenagaan kerjaan tercatat 157.313 kasus dan pekerjaan kontruksi termasuk penyumbang tertinggi kasus kecelakaan kerja. Berdasarkan data tersebut dilakukan penelitian kenapa hal itu dapat terjadi, faktor-faktor apa saja penyebab kecelakaan kerja dan bagaimana system perencanaan dan penanggulangan kecelakaan kerja pada proyek kontruksi. Penelitian ini menggunakan metode wawancara dan penyebaran kuisoner yang dibagikan kepada penanggung jawab keselamatan yaitu HSE. Instrumen penelitian yang digunakan mengacu pada Form HIRAC dengan 3 tahap pengisian HIRAC yaitu identifikasi bahaya, penilaian risiko dan pengengendalian bahaya. Berdasarkan analisis dan pembahasan pada proyek pembangunan Apartemen Tamansari Amarta dapat disimpulkan bahwa risiko yang paling tinggi yaitu pada pekerjaan formwork slab dan pekerjaan pemasangan kolom. Upaya pengendalian yang dilakukan yakni dengan menerapkan sistem hirarki kontrol. Dimulai dengan tahap eliminasi, dilanjutkan tahap administrasi berkaitan dengan standar operasional (SOP), dan yang terakhir yaitu pemakaian alat pelindung diri (APD).
\end{abstract}

Kata kunci: manajemen risiko, HIRAC, kecelakaan kerja

\section{PENDAHULUAN}

Dewasa ini, pembangunan hunian gedung dan infrastruktur di Indonesia sedang gencar-gencarnya. Pembangunan proyek-proyek tersebut mengacu pada kebutuhan akan tempat tinggal dan penghidupan yang layak bagi masyarakat di seluruh pelosok Indonesia. Sebagai contoh, pembangunan Apartemen Tamansari Amarta. Apartemen ini dibangun di kawasan bisnis yaitu Jalan Palagan Tentara Pelajar Km. 7,5 Sleman. Apartemen ini berdiri di atas tanah seluas $6.366 \mathrm{~m}^{2}$ terdiri dari 2 buah tower dengan tinggi 16 lantai setiap towernya. Pada bulan Juli tahun 2018 proses pengerjaannya telah mencapai $36 \%$, yang terdiri dari pekerjaan struktur basement, struktur atas (tower), dan pekerjaan lainnya. Proyek yang dimulai pada awal tahun 2017, harus selesai pada bulan Agustus tahun 2019. Oleh karena itu, dibutuhkan sumber daya manusia dalam pengertian tenaga kerja yang handal dan tangguh mengingat terbatasnya waktu, agar proyek selesai sesuai waktu yang telah ditentukan.

Sumber daya manusia sebagai tenaga kerja tidak terlepas dari masalah-masalah yang berkaitan dengan keselamatan dan kesehatan sewaktu bekerja. Semakin tinggi suatu bangunan, maka semakin besar pula risiko kecelakaan kerja yang terjadi.

Kecelakaan kerja di proyek konstruksi bisa membuat pekerjaan berhenti, membuat rendah semangat kerja, sehingga produktifitas menurun. Maka hal ini menjadi dasar peneliti untuk mengkaji pentingnya manajemen K3, agar kecelakaan dapat ditangani dengan tepat serta mengurangi terjadinya kecelakaan kerja dengan Metode HIRAC (Hazard Identification, Risk. Assessment, and Control). 


\section{LANDASAN TEORI}

Hanafi (2006) menyatakan risiko adalah bahaya, akibat atau konsekuensi yang dapat terjadi akibat sebuah proses yang sedang berlangsung atau kejadian yang akan datang. Menurut Departemen Tenaga Kerja, kecelakaan didefinisikan sebagai suatu kejadian yang tidak diinginkan, tidak terduga yang dapat menimbulkan kerugian material, kerusakan alat atau bahan, cidera, dan korban jiwa. Menurut Ervianto (2005) tingginya angka kecelakaan kerja dalam pekerjaan konstruksi gedung, sangat merugikan berbagai pihak, khususnya tenaga kerja yang bersangkutan. Oleh karena itu, setiap perusahaan diwajibkan menerapkan Sistem Manajemen Keselamatan dan Kesehatan Kerja (SMK3) yang meliputi struktur organisasi, perencanaan, tanggung jawab, pelaksanaan, prosedur, proses, dan sumber daya yang dibutuhkan bagi pengembangan, penerapan, pencapaian, pengajian dan pemeliharaan kebijakan keselamatan dan kesehatan kerja dalam rangka pengendalian risiko yang berkaitan dengan kegiatan kerja guna terciptanya tempat kerja yang aman, efisien dan produktif (Permenaker No. 5 Tahun 1996). Penelitian ini menggunakan metode Hazard Identification Risk. Assessment Control (HIR AC) dalam proses penentuan bobot risiko. Cara pelaksanaan metode HIRAC dengan mengklasifikasikan kegiatan kerja kemudian mengidentifikasi bahaya yang terjadi, lalu menganalisis dan melakukan penilaian risiko dari setiap bahaya, dengan cara menghitung atau menaksir kemungkinan terjadinya dan keparahan bahaya, kemudian memberi keputusan apakah risiko tersebut dapat ditoleransi atau tidak serta menerapkan upaya pengendalian atas risiko yang terjadi.

Berikut ini merupakan 9 variabel yang digunakan dalam penelitian :

V1. Terjatuh dari platform.

V2. Kepala terbentur.

V3. Pekerja terjatuh dari ketinggian.

V4. Iritasi Kulit.

V5. Mata terkena percikan api.

V6. Pekerja tersandung material.

V7. Pekerja tergores, tertusuk material.

V8. Tertimpa material.

V9. Tersengat listrik.

\section{METODE}

Metode yang digunakan dalam penelitian ini adalah metode studi kasus. Tahapan penelitian meliputi tahap persiapan dengan melakukan identifikasi masalah dan survey lokasi, kegiatan pengumpulan data yaitu data primer yang diperoleh dengan pembagian kuisioner dan wawancara, serta data sekunder yang diperoleh dengan studi literatur. Berdasarkan data hasil kuisioner tahap 1 dianalisa menggunakan metode HIR AC untuk mengetahui seberapa sering risiko tersebut terjadi, selanjutnya dari hasil kuisioner tahap 2 dianalisa tingkat keparahan akibat risiko terjadi. Selanjutnya dilakukan analisa mengenai level risiko menggunakan hasil kemungkinan terjadinya risiko dengan hasil nilai keparahan untuk mengetahui level risiko yang paling tinggi. Lalu akan ditentukan upaya penanganan yang digunakan untuk merespons risiko yang terjadi.

\section{HASIL DAN PEMBAHASAN}

Berdasarkan hasil analisa yang telah dilakukan, penelitian ini bertujuan untuk menemukan risiko dominan dengan level risiko tertinggi pada proyek pembangunan Apartemen Tamansari Amarta Yogyakarta berdasarkan penilaian yang telah diberikan sampel, didapatkan hasil sebagai berikut :

1. Risiko yang paling tinggi pada proyek Tamansari Amarta yaitu pada pekerjaan formwork slab, pekerjaan pemasangan kolom, dan pabrikasi tulangan kolom. Kedua pekerjaan tersebut memiliki risiko pekerja tersandung material dan pekerja tergores atau tertusuk material. Keduanya termasuk risiko yang paling tinggi karena berdasarkan penilaian memiliki level risiko yang berada pada tingkat High Risk. Hasil analisa level risiko lengkapnya dapat dilihat pada Tabel 1.

Tabel 1. Hasil Analisa Level Risiko

\begin{tabular}{lllc}
\hline No. & \multicolumn{1}{c}{ Jenis Pekerjaan } & \multicolumn{1}{c}{ Variabel } & Level Risiko \\
\hline 1. & Pembongkaran scaffolding & Terjatuh dari platform & $\mathrm{M}$ \\
\hline & & Kepala terbentur & $\mathrm{M}$ \\
\hline 2. & Pekerjaan Pengecoran & Pekerja/fasilitas terjatuh dari ketinggian & $\mathrm{L}$ \\
\hline & & Iritasi Kulit & $\mathrm{L}$ \\
\hline & & Tersengat Listrik & $\mathrm{L}$ \\
\hline
\end{tabular}




\begin{tabular}{lllc}
\hline 3. & Pemasangan formwork slab & Pekerja tersandung material & $\mathrm{H}$ \\
\hline & & Pekerja tergores, tertusuk material & $\mathrm{H}$ \\
\hline & & Pekerja terbentur & $\mathrm{M}$ \\
\hline 4. & Pemasangan kolom & Terjatuh dari platform & $\mathrm{M}$ \\
\hline & & Pekerja tergores, tertusuk material & $\mathrm{H}$ \\
\hline 5. & Lifting material & Pekerja tersandung material & $\mathrm{H}$ \\
\hline 6. & Pabrikasi tulangan kolom & Tertimpa material & $\mathrm{M}$ \\
\hline 7. & Pekerjaan pengelasan & Pekerja tertusuk material & $\mathrm{H}$ \\
\hline & & Mata terkena percikan api & $\mathrm{L}$ \\
\hline
\end{tabular}

2. Hasil analisa level risiko yang telah dianalisa menggunakan hasil kuisioner tahap 2 menunjukan bahwa berdasarkan perhitungan level risiko yang terjadi, risiko dengan level tertinggi adalah pekerja tersandung material dan pekerja tergores/tertusuk material dengan level risiko bigh risk, sedangkan 4 variabel risiko yang lain tergolong pada level low risk dan 3 variabel sisanya tergolong pada moderate risk.

3. Hasil level risiko yang telah dianalisa menggunakan metode HIRAC menunjukan bahwa alternatif pengendalian risiko yang telah diterapkan berdasarkan hirarki pengendalian risiko adalah sebagai berikut:

a. Pengendalian yang dapat dilakukan berdasarkan hirarki proses yang pertama dilakukan yaitu eliminasi, menghilangkan sumber bahaya. Tahap eliminasi yaitu dengan membersihkan area proyek dari sampah-sampah material yang berserakan seperti Gambar 1. untuk menghindari pekerja tersandung, selain itu stek besi yang tersisa perlu dipotong agar tidak melukai pekerja.

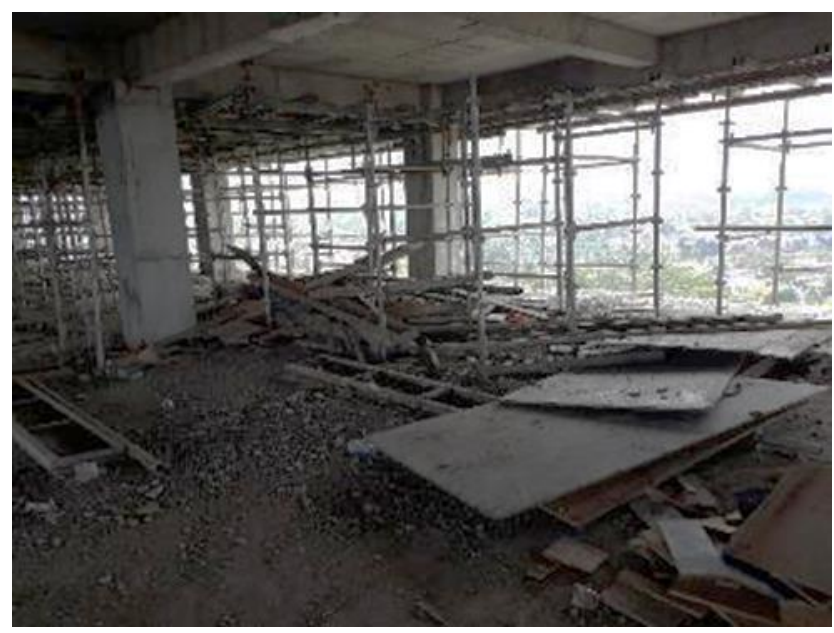

Gambar 1.

b. Setelah eliminasi, tahap selanjutnya yaitu tahap adminitrasi, yang berhubungan dengan SOP suatu pekerjaan dan kegiatan Safety Morming Talk yang diwajibkan dilaksanakan di pagi hari sebelum pekerjaan dimulai. Safety Morning Talk merupakan salah satu sarana penunjang dalam upaya mencegah terjadinya kecelakaan di tempat kerja, serta berbagai masalah pekerjaan dapat didiskusikan untuk kemudian dapat diterapkan hasil diskusi tersebut di lapangan. Selain itu, dengan adanya Safety Morming Talk dapat meningkatkan pengetahuan pekerjaan yang dihadapi dan bahaya berserta penanggulangannya, kemudian dapat meningkatkan pengetahuan tentang prosedur kerja, dan meningkatkan pengetahuan terhadap alat-alat pelindung diri.

c. Tahap yang terakhir yaitu pemakaian APD. APD wajib hukumnya untuk digunakan pekerja dalam bekerja di bidang konstruksi. Contohnya, safety belmet, safety belt, safety shoes, sarung tangan, masker (respirator), alat pelindung mata dan sebagainya terlihat pada Gambar 2. 


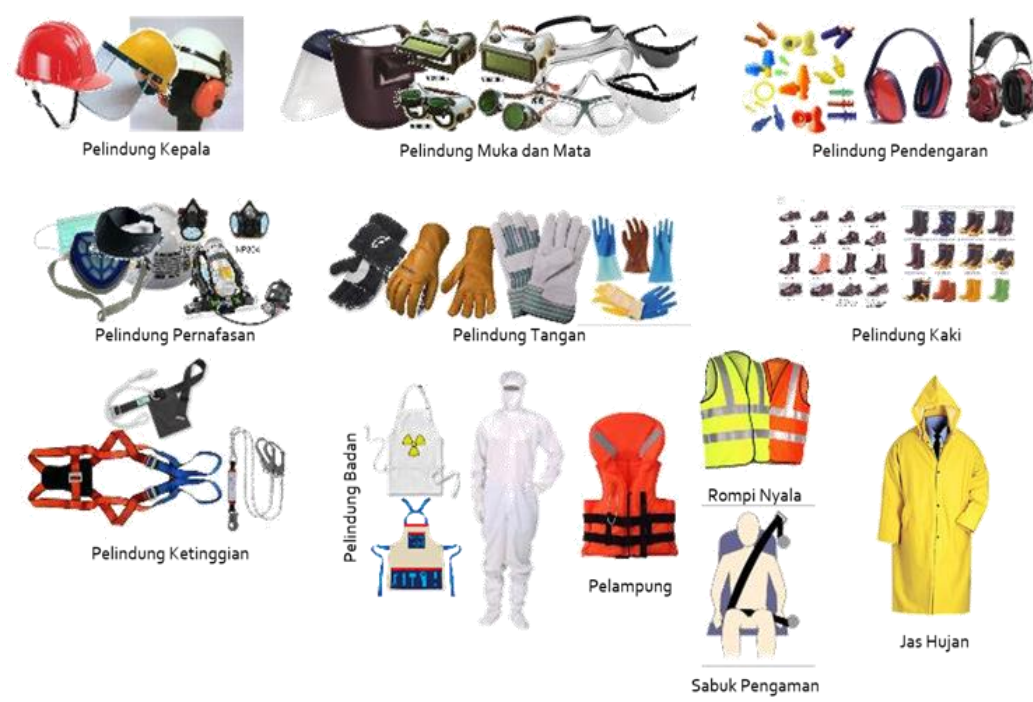

Gambar 2 .

\section{SIMPULAN}

Data hasil pengujian, analisis data, dan pembahasan terhadap hasil dari penelitian studi Manajemen Risiko Kesehatan dan Keselamatan Kerja dengan Metode HIRAC, dapat ditarik simpulan sebagai berikut: Dalam penelitian ini terdapat 9 variabel risiko kecelakaan kerja dan 9 daftar pekerjaan yang menimbulkan risiko, risiko yang paling tinggi yaitu pada pekerjaan formwork slab, pekerjaan pemasangan kolom, dan fabrikasi tulangan kolom. Ketiga pekerjaan tersebut memiliki risiko pekerja tersandung material dan pekerja tergores atau tertusuk material. Keduanya termasuk risiko yang paling tinggi karena berdasarkan penilaian memiliki level risiko yang berada pada tingkat High Risk. Upaya pengendalian yang dilakukan agar kecelakaan kerja tidak terjadi kembali yakni dengan menerapkan sistem hirarki kontrol. Dimulai dengan tahap eliminasi, kemudian melakukan tahap administrasi berkaitan dengan standar operasional kerja (SOP), dan yang terakhir yaitu pemakaian alat pelindung diri (APD).

\section{REKOMENDASI}

1. Perlu adanya penelitian mengenai berapa prosentase kerugian yang ditimbulkan suatu perusahaan akibat risiko yang terjadi.

2. Perlu adanya penelitian mengenai karakteristik pekerja yang berpengaruh pada kedisiplinan di lingkungan proyek.

\section{REFERENSI}

Adityanto, Beryl. 2013. Manajemen Risiko Keselamatan Dan Kesehatan Kerja (K3) Pada Pekerjaan Struktur Bawah Dan Struktur Atas Gedung Bertingkat. Semarang: Universitas Diponegoro.

Bagus, Yudha. 2017. Risk. Assessment K3 Pada Proses Pengoperasian Scaffolding Pada Proyek. Apartemen. Surabaya: Universitas Airlangga.

Kesehatan Kerja \& Lingkungan, Lembaga Pendidikan \& Pelatihan Keselamatan. Modul 4 Manajemen dan Administrasi K3.

Kesehatan Kerja \& Lingkungan, Lembaga Pendidikan \& Pelatihan Keselamatan. Modul 10 K3 pada Pemakaian Tangga dan Perancah.

Realty, Wika. 2017. Inspeksi Pelaksanaan Keselamatan, Kesehatan Kerja dan Lingkungan (K3L). Jakarta.

Realty, Wika. 2017. Perencanaan Keselamatan, Kesehatan Kerja dan Lingkungan (K3L Plan). Jakarta.

Realty, Wika. 2017. Petunjuk Pelaksanaan \& Penilaian Keselamatan, Kesehatan Kerja dan Lingkungan (K3L). Jakarta. 